\title{
Comportement agronomique et sanitaire de nouvelles lignées de piment (Capsicum sp) dans le Sud de la Côte d'Ivoire.
}

\author{
Fondio Lassina ${ }^{1}$, N'zi Jean-Claude $^{2}$, Kobenan Kouman ${ }^{3}$ \\ ${ }^{1}$ CNRA/Station de Recherche sur les Cultures Vivrières, 01 BP 633 Bouaké 01, Côte d'Ivoire. Tél: (225) +225 \\ 03515486. \\ 2Université Félix Houphouët-Boigny, Abidjan, Côte d'Ivoire, UFR Biosciences, 22 BP 582 Abidjan 22. Telephone: \\ +22547395620/22440307. \\ ${ }^{3}$ CNRA/Station de Recherche de Bimbresso, Laboratoire de pathologie végétale, 01 BP 1740 Abidjan 01 Côte \\ d'Ivoire, Tél : 23454176. \\ *Mail de l'auteur correspondant: nzi.jeanclaude@univ-fhb.edu.ci
}

Original submitted in on $27^{\text {th }}$ May 2015. Published online at www.m.elewa.org on $31^{\text {st }}$ August 2015 http://dx.doi.org/10.4314/jab.v92i1.4

\section{RESUME}

Objectif: Déterminer les performances agronomiques de nouvelles lignées de piment (Capsicum sp) dont huit introduites de l'AVRDC (PM14/04A, PM15/04A, PM16/04A, PM17/04A, PM51/04A, PM52/04A, PM53/04A et PM57/05A) et une variété locale utilisée comme témoin local (TL) en Station de recherche en vue de leur culture en Côte d'lvoire.

Méthodologie et résultats: 9 lignées ont été évaluées dans un dispositif en blocs de Fisher à 3 répétitions au Sud de la Côte d'Ivoire. Les données ont collectées sur les paramètres agronomiques comme le développement végétatif, le rendement et ses composants et le taux de fruits avariés) et sanitaires (taux de plants flétris et maladies fongiques). Les lignées PM17/04A, PM57/05A, PM14/04A et PM16/04A ont enregistré les meilleures performances et les rendements les plus élevés avec 8 à 12 t/ha. De plus, PM16/04A, PM57/05A et PM17/04A avec 11,1, 9,7 et 6,9\% de mortalité, ont été moins affectées par le flétrissement bactérien. Conclusion et application: Les quatre lignées de piment PM17/04A, PM14/04A, PM57/05A et PM16/04A, qui ont présenté de hauts potentiels de production avec un bon développement végétatif et une faible sensibilité au flétrissement bactérien, devront faire l'objet d'évaluations plus approfondies notamment en milieu paysan pour déterminer leur capacité d'adaptation aux conditions locales de culture en vue de leur sélection définitive. La présence maladies fongiques sur les variétés de piment a aussi été effective. Des études ultérieures pourront être aussi conduites pour confirmer la présence ou non de Cylindrocarpon sp sur le piment et de déterminer la nature du champignon indéterminé. Quant aux agents fongiques Rhizoctonia solani, Colletotrichum sp et Fusarium sp formellement identifiés, les méthodes de lutte pourront être aussi développées pour leur meilleur contrôle en culture du piment en Côte d'Ivoire.

Mots clés : Piment, Capsicum sp, lignées, comportement agronomique, flétrissement bactérien, maladies fongiques. 


\section{Fondio et al. J. Appl. Biosci. Comportement agronomique et sanitaire de nouvelles lignées de piment}

(Capsicum sp) dans le Sud de la Côte d'Ivoire.

Agronomic and sanitary behaviour of new pepper lines (Capsicum sp.) in the South of Côte d'Ivoire ABSTRACT

Objective: To determine the agronomic performance of new pepper lines (Capsicum $\mathrm{sp}$ ) in which eight introduced from AVRDC (PM14/04A, PM15/04A, PM16/04A, PM17/04A, PM51/04A, PM52/04A, PM53/04A and $\mathrm{PM} 57 / 05 \mathrm{~A}$ ) and a local variety used as a local check (TL) through their assessment in Research Station for their cultivation Côte d'Ivoire.

Methodology and results: 9 lines were evaluated in a randomized complete block design with three replications in southern Côte d'Ivoire. Data were collected on agronomic parameters such as crop development, yield and its components and non-marketable fruit rates) and sanitary parameters (rate of plants wilted plants and fungal diseases). PM17/04A, PM57/05A, PM14/04A and PM16/04A lines recorded the best performance and highest yields with 8-12 t/ha. In addition, PM16/04A, PM57/05A and PM17/04A with 11.1, 9.7 and 6.9\% mortality, were less affected by bacterial wilt.

Conclusion and Application: The four pepper lines PM17/04A, PM14/04A, PM57/05A and PM16/04A, which presented the highest production potentials (good vegetative development and low sensitiveness to the bacterial wilt), could be assessed especially on farmers' fields in order to determine their capacity of adaptation to the local conditions of production for their final selection. A presence fungal disease on pepper varieties was also effective. Subsequent studies could be conducted to confirm Cylindrocarpon sp presence on pepper and to determine the fungal agent. Concerning Rhizoctonia solani, Colletotrichum $s p$ and Fusarium sp fungal agents formally identified, some techniques could also be developed for their best control in the pepper cultivation in Côte d'Ivoire.

Key words: Pepper, Capsicum sp, lines, agronomic potentialities, bacterial wilt, fungal diseases.

\section{INTRODUCTION}

La production mondiale du piment était évaluée en 2012 par la $F A O$ à plus de 31 millions de tonnes (FAO, 2014). Avec 500000 et 110000 tonnes par an, le Nigéria et le Ghana sont les plus grand pays producteurs de piment en Afrique de l'Ouest. En Côte d'Ivoire, avec une production estimée à 32900 tonnes par an, le piment constitue avec le gombo, la tomate et l'aubergine les principaux légumes consommés et cultivés. Le piment est utilisé en alimentation (Kouassi, 2012; Koffi et al., 2014) et en médicine traditionnelle (Koffi-Nevry et al., 2012) par les populations pour sa forte teneur en capsaïcine. Ce principe piquant du piment est constitué d'une huile jaunâtre à saveur brûlante. En plus de ce principe piquant, le piment est aussi riche en éléments minéraux, en vitamines $A$ et $C$ nécessaires au bon fonctionnement de l'organisme (Leug et al., 1968; El-Ghoraba et al. 2013). Au plan économique, les prix du kilogramme de piment constamment élevés sur les marchés (entre 505 et $722 \mathrm{~F} / \mathrm{kg}$ en décembre 2012 sur les marchés de Bouaké) offrent des opportunités d'amélioration de revenus pour les producteurs. Cependant, au plan agronomique, de nombreux facteurs limitent la production du piment en Côte d'Ivoire notamment l'absence ou l'inadaptation des lignées sélectionnées disponibles dans le commerce, la sensibilité des lignées traditionnelles aux maladies et ravageurs (Sanogo \& Carpentier, 2007; Segnou et al., 2013; Zhani et al., 2013), et l'absence d'itinéraires techniques élaborés par la recherche pour cette culture. Parmi ces contraintes, l'absence ou l'inadaptation de lignée de piment adaptée aux conditions agroécologiques du pays demeure préoccupante. En effet, les lignées cultivées actuellement dans le pays sont soit les cultivars locaux peu productifs soit les lignées commerciales très sensibles aux facteurs biotiques. Dans cette situation, la recherche des lignées adaptées s'avère nécessaire (Truong et al., 2013). Ainsi, pour lever cette contrainte d'indisponibilité de matériel végétal adapté, le Centre National de Recherche Agronomique (CNRA) a introduit de nouvelles lignées de piment de l'Asian Vegetable Research Development Center l'AVRDC-The World Vegetable Center pour la sélection de lignées performantes. Le présent travail a pour objectif d'évaluer le potentiel agronomique et sanitaire de huit lignées de piment nouvellement introduites en 


\section{Fondio et al. J. Appl. Biosci. Comportement agronomique et sanitaire de nouvelles lignées de piment (Capsicum sp) dans le Sud de la Côte d'Ivoire.}

Côte d'Ivoire en comparaison avec une variété locale.

\section{MATERIEL ET METHODES}

Présentation du milieu d'étude : L'essai a été conduità la Station d'Expérimentation et de Production d'Anguédédou du Centre National de Recherche Agronomique (CNRA). Cette station de recherche est située à trente kilomètres d'Abidjan au Sud-Ouest et a pour coordonnées géographiques : $5^{\circ} 22 \mathrm{~N}, 4^{\circ} 8 \mathrm{~W}$ et $95 \mathrm{~m}$ d'altitude. Le climat de la zone d'étude est de type bimodal avec deux saisons de pluies (mars-juin et septembre-novembre) et deux saisons sèches (juilletaoût et décembre-février). Au cours de la période de l'essai, la température moyenne mensuelle a varié entre
27 et $31^{\circ} \mathrm{C}$ et l'hygrométrie moyenne mensuelle a été de $73,6 \%$. La figure 1 présente les histogrammes de la pluviométrie et les courbes des températures maxi et mini de l'année 2009 à Anguédédou. Le sol de la parcelle expérimentale est ferralitique et à texture sableuse. Une analyse d'échantillons de ce sol réalisée par le Laboratoire de Pédologie de l'École Supérieure d'Agronomie de Yamoussoukro, a montré qu'il est fortement acide et possède une teneur en matière organique bien décomposée ( $\mathrm{pH}=4,5$ et $\mathrm{C} / \mathrm{N}=10,5)$ selon Fondio et al. (2013).

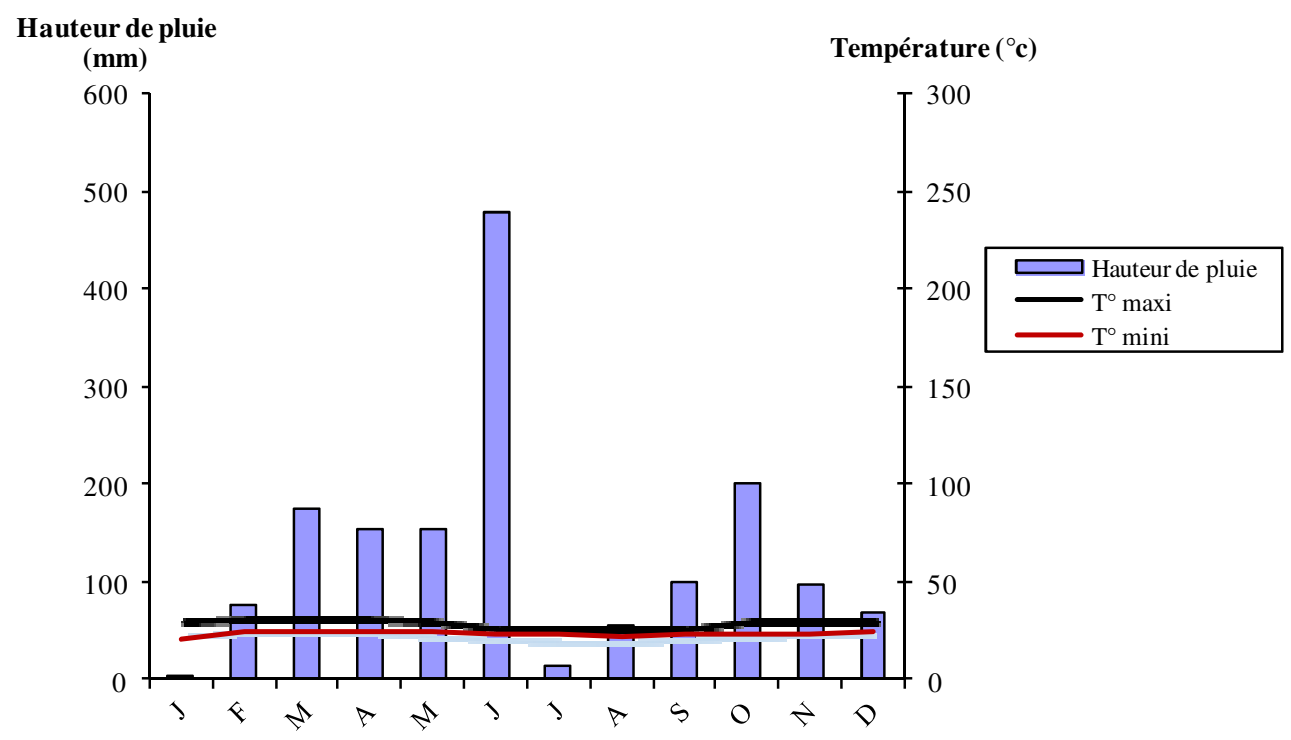

Mois

Figure 1 : Pluviométrie mensuelle, températures maxi et mini enregistrées à Anguédédou (Sud de la Côte d'Ivoire) en 2009.

Matériel végétal : L'essai a porté sur 8 lignées de piment introduites de l'Asian Vegetable Research Development Center (AVRDC) et une lignée localement cultivée par les populations d'Anguédédou. Ces piments appartiennent à l'espèce Capsicum annuum. Ces lignées de piment ont été codifiées de la manière suivante: PM pour piment, le chiffre suivant représente le numéro d'enregistrement dans les fichiers du CNRA, les 2 chiffres après la barre donne l'année d'entrée au CNRA, les lettres finales représentent les initiales des lieux de provenances (Tableau 1). La variété de piment locale dénommée 'Bakroni-froto', qui a servi de témoin a été appelé Témoin Local (TL). 


\section{Fondio et al. J. Appl. Biosci. Comportement agronomique et sanitaire de nouvelles lignées de piment (Capsicum sp) dans le Sud de la Côte d'Ivoire.}

Tableau 1 : Liste des lignées de piment évaluées à la station d'Anguédédou.

\begin{tabular}{lcc}
\hline Origines & Noms d'origine des lignées & Codes CNRA \\
\hline Anguédédou & Témoin Local & TL \\
AVRDC & PP9950-5197 & PM14/04A \\
AVRDC & PP9955-15 & PM15/04A \\
AVRDC & PP0207-7532 & PM16/04A \\
AVRDC & TPS0251 & PM17/04A \\
AVRDC & Big Sun & PM51/04A \\
AVRDC & Salmon & PM52/04A \\
AVRDC & Gbatakin & PM53/04A \\
AVRDC & PP0252-197 & PM57/05A \\
\hline
\end{tabular}

\section{Méthode d'étude}

Pratiques culturales : Les pépinières ont été réalisées le 8 Août 2009 période de la petite saison sèche dans la région d'Abidjan pour éviter la période des grandes pluies. Pour ce faire une planche de $4 \mathrm{~m}$ de long et de 1 $m$ de large a été confectionnée après un labour manuel du sol. La planche a été désinfectée avec du Furadan $5 \mathrm{G}$ à raison de $50 \mathrm{~g} / \mathrm{m}^{2}$ et fertilisée avec de l'engrais NPK10$18-18$ à la dose de $20 \mathrm{~g} / \mathrm{m}^{2}$. Les graines de piment ont été semées en lignes distantes de $10 \mathrm{~cm}$ avec $5 \mathrm{~cm}$ entre les poquets sur la ligne. Après le semis, la planche fût recouverte pendant 3 jours de feuilles de palmier à huile désinfectées avec un mélange de Manèbe (avec pour matière active, Manate 80 ) à raison de $20 \mathrm{~g} / \mathrm{L}$ d'eau et du Systoate (Diméthoate) à la dose de $10 \mathrm{ml} / \mathrm{L}$ d'eau. Après la levée des graines, une ombrière a été construite avec les feuilles de palmier à huile à une hauteur de $80 \mathrm{~cm}$ du sol. A une semaine du repiquage, l'ombrière a été allégée, en diminuant la quantité de feuilles et complètement supprimée à deux jours du repiquage. La pépinière a été régulièrement arrosée. Les plants ont été repiqués après plus d'un mois de pépinière, le 10 septembre 2009, sur des planches confectionnées à la daba. Celles-ci ont été enrichies par une fumure de fond de $250 \mathrm{~kg} / \mathrm{ha}$ d'engrais minéral NPK10-18-18 et désinfectées à raison de $20 \mathrm{~g}$ de Furadan $5 \mathrm{G}$ par poquet. Pendant la culture, une fumure d'entretien à 30,60 et 90 jours après le repiquage (JAR) a été apportée sous forme d'un mélange de $100 \mathrm{~kg} / \mathrm{ha}$ d'urée et $100 \mathrm{~kg} / \mathrm{ha}$ de Sulfate de potasse. Des sarclages ont été réalisés au besoin pour lutter contre l'enherbement. Des traitements phytosanitaires ont été effectués tous les 15 jours avec un mélange de deltaméthrine à raison de $1 \mathrm{~L} / \mathrm{ha}$ et au Manate 80 à raison de $3,5 \mathrm{~kg} / \mathrm{ha}$ pour les prévenir les attaques des maladies et insectes.

Dispositif expérimental : L'essai a été disposé en blocs de Fisher à 3 répétitions. La parcelle élémentaire était

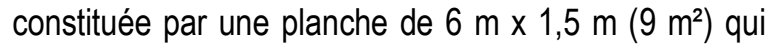
comportait 24 plants repiqués en doubles lignes à raison de $0,5 \mathrm{~m}$ entre lignes et $0,5 \mathrm{~m}$ sur la ligne. La distance entre deux parcelles élémentaires consécutives était de $0,5 \mathrm{~m}$. Autour de l'essai, une bordure de $1 \mathrm{~m}$ de large avait été repiquée avec les plants de piment de la variété témoin.

Paramètres agronomiques et sanitaires observés au champ : Au plan agronomique, les observations ont porté sur l'appréciation du développement des plants à 60 jours après le repiquage (stade de fructification), les délais de stades phénologiques et les composantes du rendement. Le développement des plants a été apprécié par la notation visuelle de l'état végétatif des plants sur l'échelle de 1 à 5 (avec $1=$ très mauvais développement des plants, 2=mauvais développement, 3= développement moyen, $4=$ bon développement et $5=$ très bon développement des plants). Les plants moins développés sont chétifs et les plus développés sont vigoureux sans attaque de maladie apparente. Les paramètres phénologiques relevés ont été le délai semisfloraison, le délai semis-date de première récolte, le délai semis-date de dernière récolte. Les composantes du rendement déterminées ont été le nombre de fruits récoltés, nombre de fruits par pied, poids total des fruits récoltés, poids moyen des fruits, le nombre et le poids des fruits avariés. Pour cela, à chaque récolte par parcelle élémentaire, tous les fruits récoltés étaient comptés et pesés. A la fin des récoltes, le nombre et le poids total des fruits récoltés, le poids moyen des fruits et le rendement en fruits ont été déterminés. Au plan sanitaire, les observations ont porté sur la sensibilité des plants au flétrissement bactérien et la détermination des maladies fongiques inféodées à ces lignées de piment. La sensibilité des lignées de piment au flétrissement bactérien a été déterminée par le comptage du nombre de plants flétris durant la phase végétative (du repiquage au stade de la fructification). Pour s'assurer que les plants de piment sont effectivement morts du flétrissement bactérien, nous avons utilisé le test du kit (Lateral Flow Device) LFD qui est une solution spécifique 


\section{Fondio et al. J. Appl. Biosci. Comportement agronomique et sanitaire de nouvelles lignées de piment (Capsicum sp) dans le Sud de la Côte d'Ivoire.}

à Ralstonia solanacearum, la bactérie responsable du flétrissement des plants (Figure 2). Ce test a consisté à déposer une goutte de solution extraite d'un broyat d'une partie de la tige du plant flétris sur un papier buvard contenant la solution spécifique du Ralstonia. La présence de la bactérie est détectée par un virement au bleu. En cas d'absence de la bactérie dans la tige, il n'y a aucun virement de couleur.

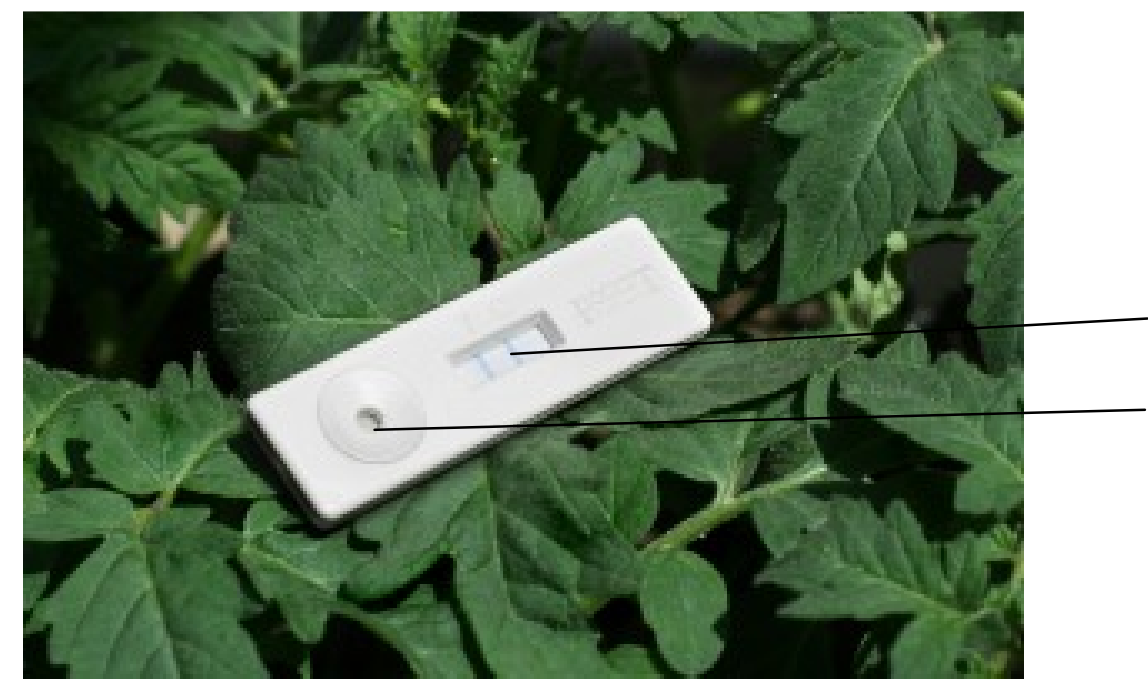

Zone de lecture du virement de couleur

Zone de dépôt des gouttes du broyat de la tige du plant flétris

Figure 2 : Présentation de 'Lateral Flow Device' l'appareil de détection de la présence de Ralstonia solanacearum dans le plant de piment flétri.

La détermination des maladies fongiques aux lignées de piment a été effectuée par l'isolement des champignons au laboratoire.

Préparation des milieux de culture : Deux milieux de culture ont servi à l'isolement des agents pathogènes au laboratoire. II s'agit du milieu PDA complet et du milieu d'eau gélosée. Le milieu PDA est composé de $30 \mathrm{~g}$ d'Agar, $50 \mathrm{~g}$ de pomme de terre et $50 \mathrm{~g}$ de glucose dissous dans $100 \mathrm{ml}$ d'eau distillée, et le milieu d'eau gélosée composée de $3 \mathrm{~g}$ d'Agar dissous dans $20 \mathrm{ml}$ d'eau distillée. Ces deux milieux ont été stérilisés à l'autoclave à $121^{\circ} \mathrm{C}$ pendant $30 \mathrm{~min}$ à la pression de 1 bar. Ils ont été ensuite coulés après refroidissement dans des boîtes de Pétri de $90 \mathrm{~mm}$ de diamètre stérilisées au préalable à l'étuve à $140^{\circ} \mathrm{C}$.

Désinfection des explants prélevés au champ: Les feuilles, les tiges et les fruits présentant des symptômes de la maladie ont été prélevés au champ, puis désinfectés au laboratoire par trempage dans de l'eau de javel diluée (1/10) pendant $5 \mathrm{~min}$, suivi de trois rinçages de 3 min dans de l'eau distillée stérile. Ces désinfections ont pour but d'éliminer surtout les bactéries de surfaces des organes.

Ensemencement et purification des champignons : Après désinfection, les feuilles, les tiges et les fruits présentant des symptômes ont été ensemencés puis purifiés. Pour ce faire, deux méthodes ont été utilisées.
Pour la première méthode, les explants ont été déposés sur le milieu PDA. Les boîtes ont été scellées avec du ruban adhésif. Elles ont été ensuite conservées dans une salle de culture, à une température de $25^{\circ} \mathrm{C}$. Quatre boîtes ont été ensemencées pour chaque symptôme en fonction des organes. Pour certains champignons (comme Colletotrichum par exemple), une deuxième méthode a été utilisée. Elle a consisté à coller les lésions aqueuses contenant les spores des champignons sur un milieu d'eau gélosée. Puis, sous un microscope les conidies ont été prélevées et transférées sur un milieu PDA complet. Les champignons obtenus par ces méthodes ont été purifiés. Après 3 jours, sur le front de croissance à l'aide d'un scalpel, une partie a été transférée sur un milieu de culture neuf en un seul point au centre de la boîte de Pétri de $90 \mathrm{~mm}$ de diamètre.

Identification des champignons : L'identification des aspects morphologiques des isolats a consisté à déterminer les caractères culturaux des champignons tels que la texture du thalle et la couleur. Pour cela, une photographie du développement de chaque champignon sur le milieu de culture a été effectuée. Pour l'identification microscopique, un fragment de chaque souche en culture, a été monté entre lame et lamelle 


\section{Fondio et al. J. Appl. Biosci. Comportement agronomique et sanitaire de nouvelles lignées de piment (Capsicum sp) dans le Sud de la Côte d'Ivoire.}

dans une goutte de bleu de méthylène. La forme des spores, ainsi que le mycélium (colorés ou non, cloisonnés ou non) ont été observés au microscope sur la base des clés d'identification des champignons de Barnett et al. (1972).

\section{RESULTATS}

Développement végétatif des plantes : La différence entre le développement végétatif des plants des lignées de piment était significative au stade de la fructification. Selon le tableau 2, les plants des lignées PM57/05A, PM17/04A, PM16/04A et PM14/04A avec une note moyenne de 4,7 ont présenté un très bon développement
Analyse des données : Les résultats des observations et mesures agronomiques ont été analysés à l'aide du Logiciel SAS (SAS, 2003). Une analyse de variance a été effectuée pour déterminer s'il y avait une différence entre les valeurs et les moyennes ont été ensuite séparées par la méthode de Duncan au seuil de $5 \%$.

végétatif. Ils étaient vigoureux et presque exempts d'attaques de maladies ou d'insectes. Le développement végétatif était bon pour les plants des lignées PM52/04A et PM15/04A avec une note de 4 et 3,7. Quant aux plants des lignées PM51/04A, TL et PM53/04, le développement végétatif était moyen avec une note moyenne de 3 à 3,3 .

Tableau 2: Développement végétatif des plants des lignées de piment à 60 jours après le repiquage (JAR)

\begin{tabular}{lc}
\hline Lignées de piment & État végétatif à 60JAR \\
\hline PM57/05A & $4,7 a^{*}$ \\
PM17/04A & $4,7 \mathrm{a}$ \\
PM16/04A & $4,7 \mathrm{a}$ \\
PM14/04A & $4,7 \mathrm{a}$ \\
PM52/04A & $4,0 \mathrm{ab}$ \\
PM15/04A & $3,7 \mathrm{ab}$ \\
PM51/04A & $3,3 \mathrm{~b}$ \\
TL & $3,3 \mathrm{~b}$ \\
PM53/04 & $3,0 \mathrm{~b}$ \\
\hline Moyenne & 4 \\
Probabilité & 0,02 \\
CV (\%) & 2 \\
\hline
\end{tabular}

Délais des stades phénologiques des lignées de piment: Selon le tableau 3, la différence entre les lignées de piment était significative pour les délais de 50 $\%$ de floraison, de première récolte, de dernière récolte et la durée de la production. Les plants de PM14/04A, PM15/04A et PM17/04A ont fleuri en 34 JAR et ceux de PM16/04A en 38 JAR. Le Témoin Local, PM51/04A, PM52/04A, PM53/04A et PM57/05A ont fleuri entre 40 et $57 \mathrm{JAR}$. La première récolte est intervenue à $105 \mathrm{JAR}$ pour PM14/04A, PM15/04A, PM16/04A et PM52/04A, à 108 JAR pour PM17/04A, à 110 JAR pour le Témoin Local et PM57/05A. Les lignées PM57/05A et PM51/04A plus tardives ont eu leur première récolte à 123 et 129 JAR. La dernière récolte de PM15/04A a eu lieu à 123 JAR, et celle des autres lignées entre 151 et 162 JAR. La durée de la production s'est située entre 18 et 61 jours pour l'ensemble des lignées évaluées.
Rendement des lignées de piment évaluées : ॥ est noté dans le tableau 4 que la différence entre les lignées de piment était significative pour le nombre de récoltes, le nombre de fruits par pied, le poids moyen du fruit et le rendement. Pour l'ensemble des lignées évaluées, il y a eu entre 5 et 13 récoltes. PM14/04A, PM17/04A et TL ont enregistré 13 et 12 récoltes. Les lignées PM14/04A, PM17/04A et PM57/05A ont produit le plus grand nombre de fruits par pied avec 67,60 et 56 fruits contre 5 pour PM15/04A qui a produit le nombre de fruits le plus faible, et 49 fruits pour le Témoin Local (TL). Le poids moyen des fruits a varié entre 2,3 et 14,7 g. Les lignées PM17/04A, PM57/05A, PM14/04A et PM16/04A ont eu un rendement en fruits supérieur à celui du témoin $T L$ qui a obtenu 4,3 tha. Les plus faibles rendements ont été notés avec PM51/04A, PM53/04A, PM52/04A et PM15/04A qui ont entre 0,87 et 1,4 t/ha. 


\section{Fondio et al. J. Appl. Biosci. Comportement agronomique et sanitaire de nouvelles lignées de piment (Capsicum sp) dans le Sud de la Côte d'Ivoire.}

Tableau 3 : Délai de $50 \%$ floraison, délai de première récolte, délai de dernière récolte et durée de la production des lignées de piment évaluées à la Station d'Anguédédou au Sud de la Côte d'Ivoire.

\begin{tabular}{lcccc}
\hline Lignées & $\begin{array}{c}\text { Délai de } 50 \% \text { floraison } \\
(\mathrm{JAR})\end{array}$ & $\begin{array}{c}\text { Délai de première } \\
\text { récolte }(\mathrm{JAR})\end{array}$ & $\begin{array}{c}\text { Délai de dernière } \\
\text { récolte }(\mathrm{JAR})\end{array}$ & $\begin{array}{c}\text { Durée de la } \\
\text { production }(\mathrm{J})\end{array}$ \\
\hline PM52/04A & $57^{\mathrm{a}}$ & $105^{\mathrm{b}}$ & $151^{\mathrm{b}}$ & $46^{\mathrm{ab}}$ \\
PM57/05A & $51^{\mathrm{ab}}$ & $110^{\mathrm{b}}$ & $158^{\mathrm{ab}}$ & $48^{\mathrm{ab}}$ \\
TL & $51^{\mathrm{ab}}$ & $110^{\mathrm{b}}$ & $162^{\mathrm{ab}}$ & $52^{\mathrm{a}}$ \\
PM53/04A & $49^{\mathrm{abc}}$ & $123^{\mathrm{a}}$ & $162^{\mathrm{ab}}$ & $39^{\mathrm{bc}}$ \\
PM51/04A & $40^{\mathrm{bc}}$ & $129^{\mathrm{a}}$ & $157^{\mathrm{ab}}$ & $28^{\mathrm{cd}}$ \\
PM16/04A & $38^{\mathrm{bc}}$ & $105^{\mathrm{b}}$ & $166^{\mathrm{a}}$ & $61^{\mathrm{a}}$ \\
PM17/04A & $34^{\mathrm{c}}$ & $108^{\mathrm{b}}$ & $166^{\mathrm{a}}$ & $58^{\mathrm{a}}$ \\
PM14/04A & $34^{\mathrm{a}}$ & $105^{\mathrm{b}}$ & $166^{\mathrm{a}}$ & $61^{\mathrm{a}}$ \\
PM15/04A & $34^{\mathrm{c}}$ & $105^{\mathrm{b}}$ & $123^{\mathrm{c}}$ & $18^{\mathrm{d}}$ \\
\hline Moyenne & 43 & 111 & 157 & 46 \\
P & 0,017 & 0,001 & 0,0001 & 0,0001 \\
CV (\%) & 19,1 & 3,5 & 4,7 & 19 \\
\hline
\end{tabular}

*Les chiffres, dans la même colonne, affectés de la même lettre, ne diffèrent pas significativement au seuil de $5 \%$ (Test de Duncan)

Tableau 4 : Nombre de récolte, nombre de fruits récoltés par pied, poids moyen et rendement des lignées de piment évaluées à la Station d'Anguédédou au Sud de Côte d'Ivoire.

\begin{tabular}{lcccc}
\hline Lignées & Nombre de récoltes & $\begin{array}{c}\text { Nombre de fruits par } \\
\text { pied }\end{array}$ & $\begin{array}{c}\text { Poids moyen du fruit } \\
(\mathrm{g})\end{array}$ & $\begin{array}{c}\text { Rendement } \\
(\mathrm{t} / \mathrm{ha})\end{array}$ \\
\hline PM14/04A & $13^{\mathrm{a}}$ & $67^{\mathrm{a}}$ & $7,7^{\mathrm{cde}}$ & $10,8^{\mathrm{a}}$ \\
PM16/04A & $13^{\mathrm{a}}$ & $37^{\mathrm{abc}}$ & $10,2^{\mathrm{bc}}$ & $8,7^{\mathrm{ab}}$ \\
PM17/04A & $13^{\mathrm{a}}$ & $60^{\mathrm{ab}}$ & $8,5^{\mathrm{cd}}$ & $11,9^{\mathrm{a}}$ \\
TL & $12^{\mathrm{ab}}$ & $49^{\mathrm{ab}}$ & $5,4^{\mathrm{e}}$ & $4,3^{\mathrm{bc}}$ \\
PM57/05A & $12^{\mathrm{ab}}$ & $56^{\mathrm{ab}}$ & $8,5^{\mathrm{cd}}$ & $10,9^{\mathrm{a}}$ \\
PM53/04A & $10^{\mathrm{bc}}$ & $18^{\mathrm{cd}}$ & $6,4^{\mathrm{de}}$ & $0,88^{\mathrm{c}}$ \\
PM52/04A & $9^{\mathrm{cd}}$ & $31^{\mathrm{bcd}}$ & $2,3^{\mathrm{f}}$ & $1,6^{\mathrm{c}}$ \\
PM51/04A & $7^{\mathrm{de}}$ & $14^{\mathrm{cd}}$ & $14,7^{\mathrm{a}}$ & $0,87^{\mathrm{c}}$ \\
PM15/04A & $5^{\mathrm{e}}$ & $5^{\mathrm{d}}$ & $11,6^{\mathrm{b}}$ & $1,4^{\mathrm{c}}$ \\
\hline Moyenne & 10 & 37 & 8,4 & 5,7 \\
P & 0,0001 & 0,0019 & 0,0001 & 0,0014 \\
CV (\%) & 12,96 & 43,6 & 16,3 & 46,2 \\
\hline
\end{tabular}

*Les chiffres, dans la même colonne, affectés de la même lettre, ne diffèrent pas significativement au seuil de $5 \%$ (Test de Duncan).

Sensibilité des lignées de piment au flétrissement bactérien: Les résultats de l'analyse de variance indiquent que la différence entre les lignées de piment était significative pour le taux de mortalité des plants due au flétrissement bactérien (Figure 3). Le taux de mortalité a varié entre 6,9 et $84,7 \%$ avec une répartition des lignées de piment selon leur degré de sensibilité à la maladie en 3 groupes (Tableau 5) :
- les lignées hautement sensibles comprenant PM51/04A et PM53/04A avec 84,7 et $68 \%$ de mortalité ; - les lignées moyennement sensibles composées de TL, PM15/04A et PM52/04A avec 30,6, 26,4 et 22,2\% de mortalité ;

- les lignées tolérantes composées de PM14/04A, PM16/04A, PM57/05A et PM17/04A avec 19,4, 11,1, 9,7 et $6,9 \%$ de mortalité. 
Fondio et al. J. Appl. Biosci. Comportement agronomique et sanitaire de nouvelles lignées de piment (Capsicum sp) dans le Sud de la Côte d'Ivoire.

Tableau 5 : Taux de plants flétris à 30 JAR des lignées de piment évaluées à la Station d'Anguédédou au Sud de la Côte d'Ivoire.

\begin{tabular}{ll}
\hline Lignées & Taux de plants flétris $(\%)$ \\
\hline PM51/04A & $84,7^{a^{*}}$ \\
PM53/04A & $68^{\mathrm{b}}$ \\
TL & $30,6^{\mathrm{c}}$ \\
PM15/04A & $26,4^{\text {cd }}$ \\
PM52/04A & $22,2^{\text {cd }}$ \\
PM14/04A & $19,4^{\text {cde }}$ \\
PM16/04A & 11,1 de \\
PM57/05A & $9,7^{\mathrm{e}}$ \\
PM17/04A & $6,9^{\mathrm{e}}$ \\
\hline Moyenne & 31 \\
Probabilité & 0,0001 \\
CV (\%) & 26,7 \\
\hline
\end{tabular}

*Les chiffres, dans la même colonne, affectés de la même lettre, ne diffèrent pas significativement au seuil de $5 \%$ (Test de Duncan).

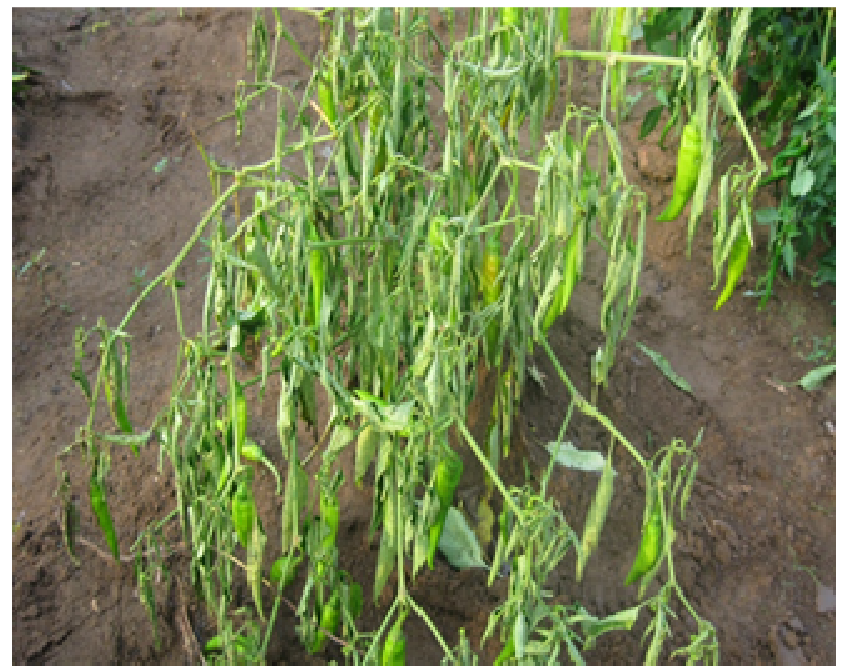

Figure 3 : Un plant de piment (PM14/04A) mort dû au flétrissement bactérien

\section{Champignons observés au laboratoire}

Champignons foliaires sur les feuilles : Sur les feuilles des accessions PM15/04A, PM16/04A, PM17/04A, PM57/05A, PM14/04A et PM52/04A diverses tâches nécrotiques plus ou moins rondes, de couleur brune avec une petite tache blanche au centre ont été observées. Les lésions mesuraient $5 \mathrm{~mm}$ à $8 \mathrm{~mm}$ de diamètre.
Plusieurs tâches confluaient couvrant ainsi de grandes surfaces foliaires. Certaines feuilles tombaient prématurément même si elles ne portaient que peu de tâches et d'autres présentant de légères brûlures entourés par des halos jaunes restaient sur la tige (Figure 4). 


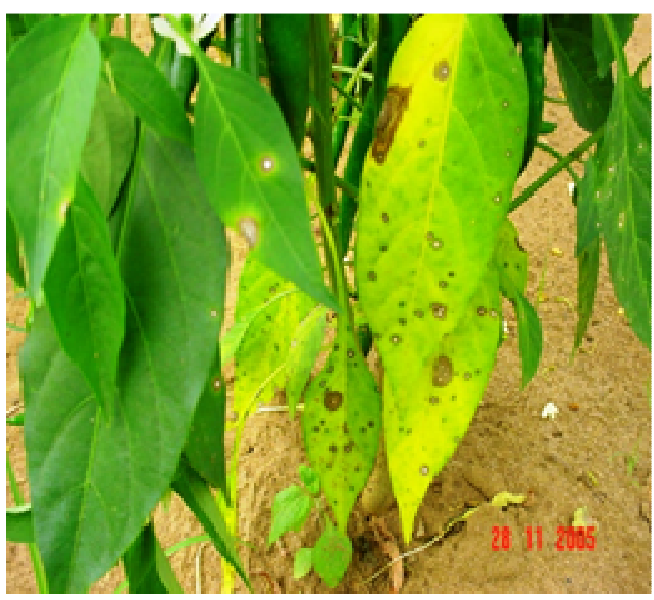

Figure 4 : Feuilles de piment (PM15/04A) présentant des taches nécrotiques entourées par des halos jaunes

Avec la première méthode d'isolement sur milieu PDA, trois champignons ont été isolés des lésions nécrotiques plus ou moins rondes de couleur brune des feuilles des lignées PM15/04A, PM17/04A, PM16/04A, PM57/05A et PM52/04A. Par contre, aucun champignon n'a été isolé des feuilles de PM14/04A, PM51/04A, PM53/04A et du Témoin Local. Le premier champignon a présenté un thalle blanc cotonneux. Au microscope, les mycelia étaient ramifiés et cloisonnés avec une absence de fructification. Ce champignon n'a pas pu être identifié (Figures 5 et 6 ). Un deuxième champignon dont le thalle est blanc avec un fond rouge-violacé a été aussi isolé des feuilles des mêmes lignées. Les mycelia de ce champignon, vus au microscope sont ramifiés et cloisonnés. Les conidiophores sont droits, minces avec

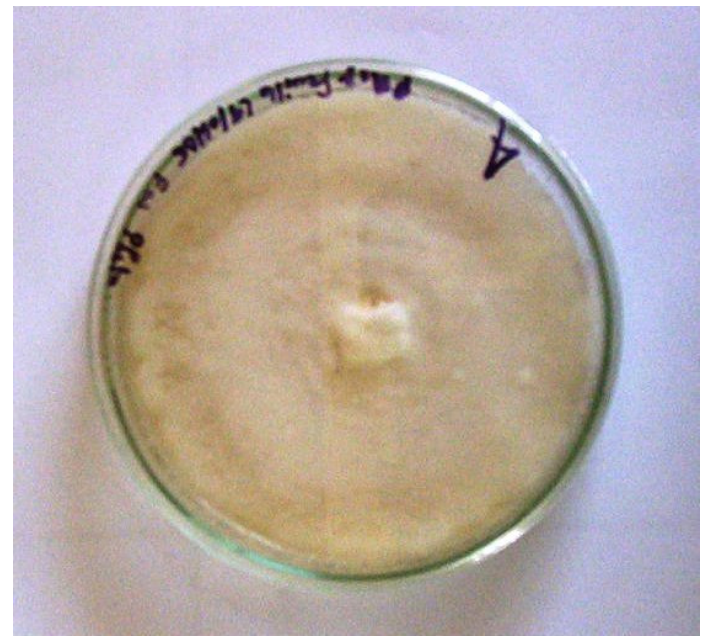

Figure 5: Thalle blanc cotonneux de non identifié isolé sur les feuilles de PM17/04A (x400). des branches irrégulières terminées par des phialides qui sont plus minces et plus courts que les conidiophores. Les conidies forment un amas autour de la phialide. Les dimensions extrêmes des conidies cylindriques à bouts arrondis étaient de 80-110 $\mu \times 20-25 \mu$. Ce champignon appartiendrait au genre Cylindrocarpon (Figures 7 et 8). Enfin, le troisième champignon a présenté un thalle noir. Au microscope, les fructifications étaient inexistantes, les mycélia sont bruns cloisonnés et les ramifications forment des angles droits. Ce champignon appartiendrait à l'espèce Rhizoctonia solani (Figures 9 et 10). Avec la seconde méthode d'isolement aucun champignon ne s'est développé sur le milieu de culture d'aucune lignée de piment.

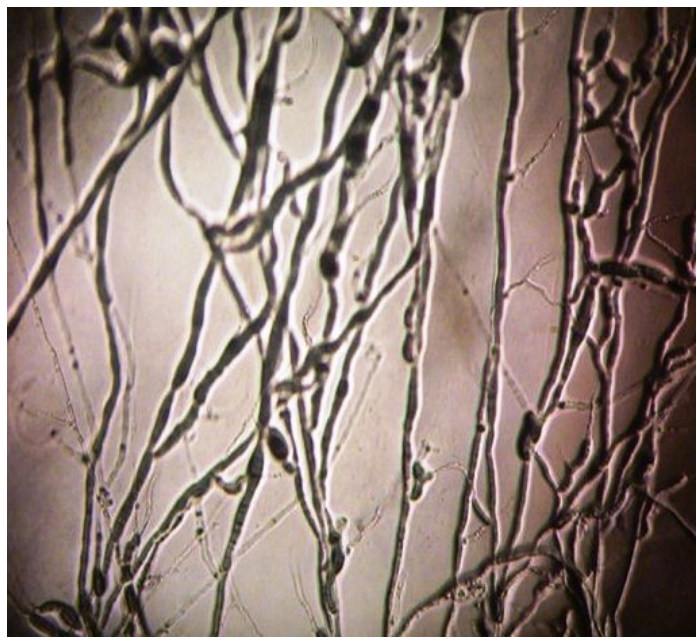

Figure 6: Mycélium cloisonné et ramifié champignon de champignon non identifié isolé sur les feuilles de PM17/04A (x400). 


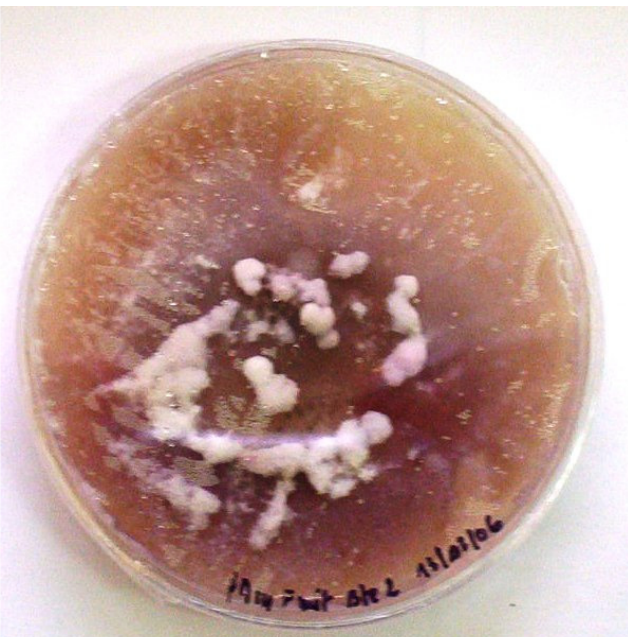

Figure 7 : Thalle blanchâtre avec un fond de Cylindrocarpon sp. isolé sur les fruits de PM14/04A (x400).

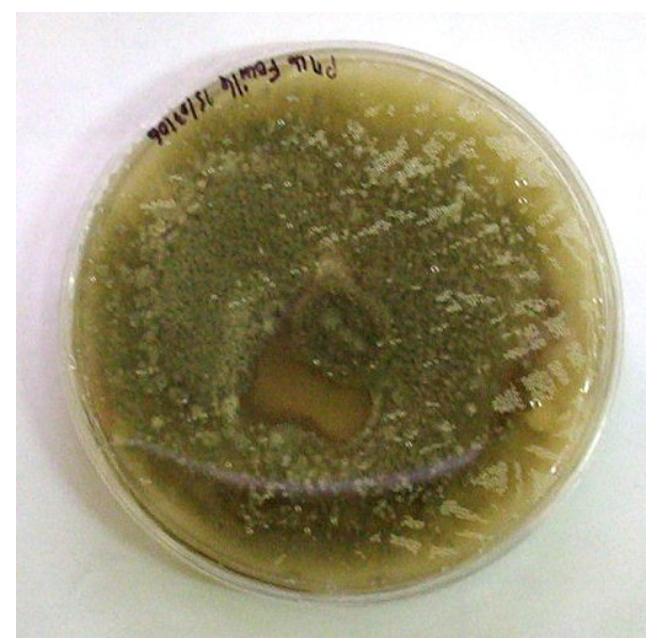

Figure 9 : Thalle noirâtre de Rhizoctonia solani isolé sur feuille de PM16/04A (x400)

Champignons des fruits : Sur les fruits des lignées de PM15/04A, PM57/05A, PM14/04A et PM17/04A, les parties infectées devenaient d'abord vert foncé et aqueux puis l'infection s'étendait pour couvrir rapidement tout le fruit. Par la suite, le fruit pourrissait tout en restant attaché à la plante. A partir de la méthode d'isolement sur milieu PDA, trois champignons ont été isolés sur les tâches arrondies et aqueuses prélevées des lésions de fruits des lignées PM15/04A, PM14/04A, PM17/04A, PM57/04A et PM16/04A. Aucun champignon n'a été, par contre, isolé des fruits de PM51/04A, PM52/04A, PM53/04A et du Témoin Local. Le premier champignon a présenté un thalle blanc laiteux. Au microscope, les mycélia sont

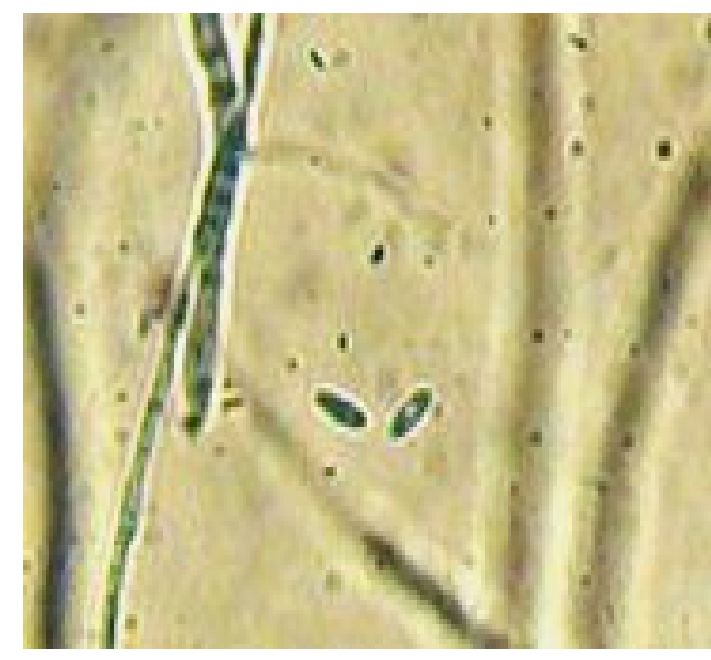

Figure 8 : Conidies de Cylindrocarpon sp. violet isolés sur les fruits de PM14/04A (x400).

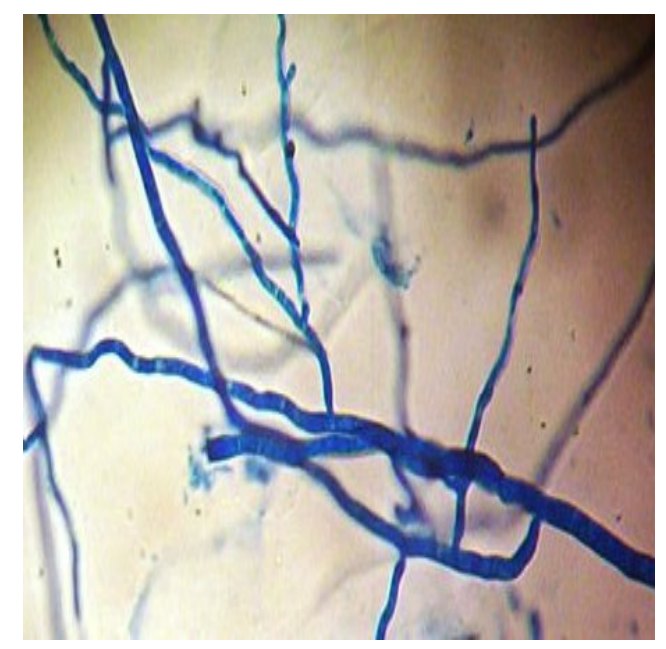

Figure 10 : Mycélium cloisonné et ramifié de Rhizoctonia solani isolé sur feuille de PM16/04A (x400)

cloisonnés et ramifiés. Les macroconidies sont arquées de formes lunaires et hyalines avec trois cloisons par conidie. Les dimensions extrêmes étaient de 190-300 $\mu \mathrm{x}$ 40-80 $\mu$. Quant aux microconidies, elles sont de forme ovale, hyalines non cloisonnées. Les dimensions extrêmes étaient de 80-110 $\mu$ x 50-70 $\mu$. Ce champignon appartiendrait au genre Fusarium sp (Figures 11 et 12). Les deux autres champignons isolés, Cylindrocarpon $\mathrm{sp}$ et Rhizoctonia solani, ont présenté les mêmes caractéristiques que ceux décrits dans le cas des feuilles. Avec la seconde méthode d'isolement avec milieu eau gélosée, Colletotrichum sp. a été isolé sur les fruits présentant des tâches arrondies et aqueuses. Ainsi, les 


\section{Fondio et al. J. Appl. Biosci. Comportement agronomique et sanitaire de nouvelles lignées de piment}

(Capsicum sp) dans le Sud de la Côte d'Ivoire.

conidies sont hyalines, ovoïdes ou rectangulaires et leurs dimensions extrêmes sont de 140-200 $\mu \times 40-50 \mu$

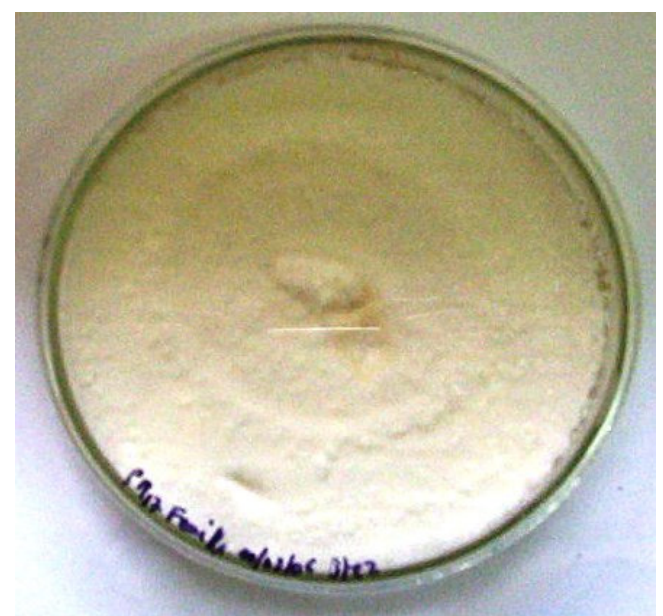

Figure 11 : Thalle blanc laiteux de Fusarium sp isolé sur fruit de la lignée lignée PM17/04A (x400)

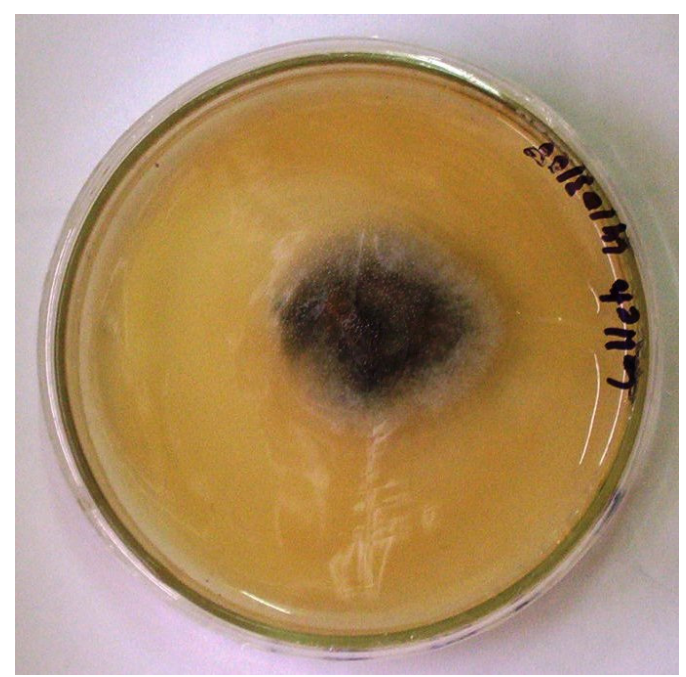

Figure 13 : Thalle brunâtre de Colletotrichum sp isolé sur fruit de PM57/05A (x400)

Champignons de la tige: Sur les tiges des lignées PM15/04A et PM16/04A, les symptômes ont été observés. Ils se sont manifestés par un flétrissement rapide des plants de tous âges sans jaunissement préalable des feuilles. Au niveau du collet, des nécroses noires contournaient la tige. Les vaisseaux ne
(Figures 13 et 14).

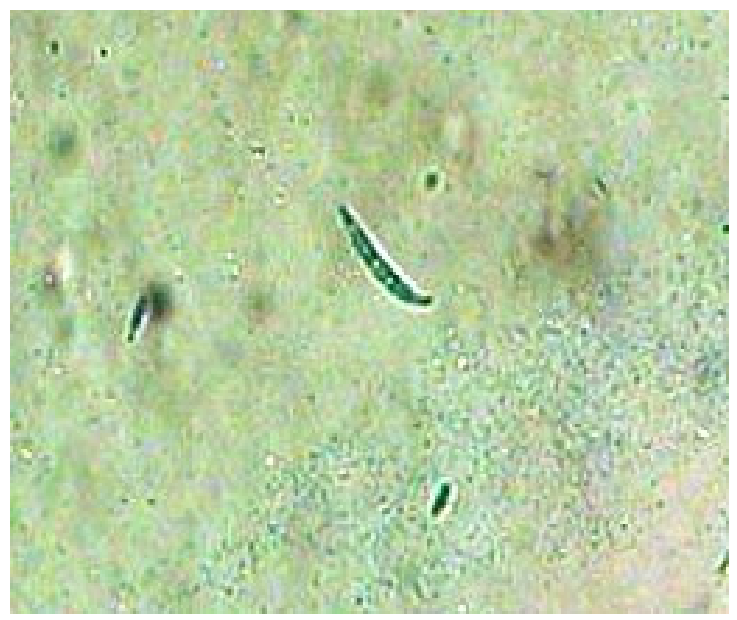

Figure 12 : Macro et microconidie. de Fusarium sp isolées sur fruit de la lignée PM17/04A (x400)

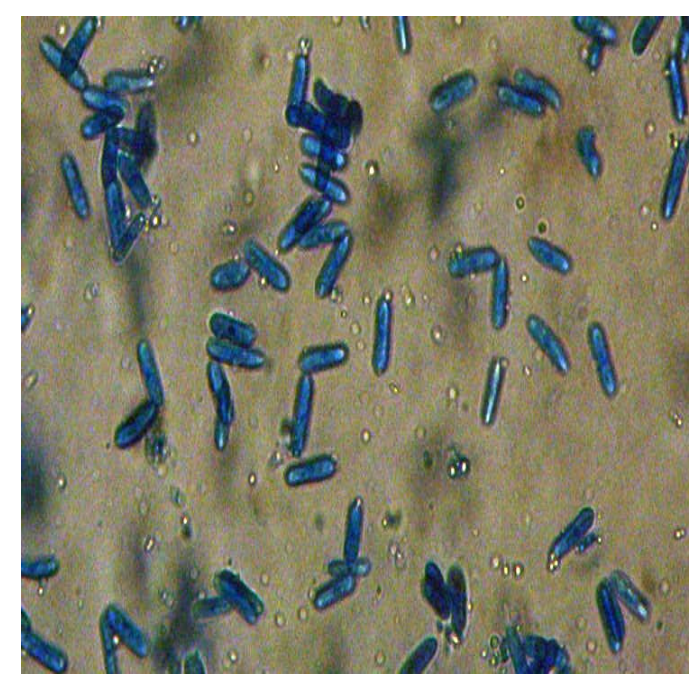

Figure 14: Conidies cloisonnées de Colletotrichum sp isolées sur fruits de PM57/05A (x400)

présentaient pas de brunissement. Avec la méthode d'isolement sur milieu PDA, le champignon Cylindricarpon sp. a été isolé sur les tiges présentant des nécroses du collet des lignées PM51/04A et PM15/04A lorsque Rhizoctonia solani a été isolé sur les tiges de PM16/04A. 


\section{Fondio et al. J. Appl. Biosci. Comportement agronomique et sanitaire de nouvelles lignées de piment}

(Capsicum sp) dans le Sud de la Côte d'Ivoire.

\section{DISCUSSION}

Expression des paramètres agronomiques: La différence significative observée entre les lignées de piment par rapport au développement végétatif résulterait de la différence dans leur capacité d'adaptation au milieu. Plus le milieu de culture est favorable aux plantes plus elles se développent. En conséquence, celles ayant supporté les conditions du milieu se seraient les plus développées. En outre, le développement végétatif peut être aussi de nature génétique. II existe des variétés aux plants de grande envergure et de grande taille et d'autres aux plants de petite envergure et de petite taille. Zhani et al. (2015) ont établi en Tunisie des différences significatives entre le développement végétatif de diverses accessions de piment et expliqué que ces différences seraient liées aux génotypes et à l'environnement qui peuvent influencer l'expression des paramètres végétatifs. En Côte d'Ivoire, des différences similaires entre le développement végétatif de diverses variétés de tomate avaient été aussi démontrées sur la même Station de recherche d'Anguédédou par Fondio et al. (2013). S'agissant des paramètres phénologiques, les différences significatives observées entre les lignées de piment pour le délai de $50 \%$ floraison, de première et de dernière récolte seraient aussi de nature génétique. II existe des lignées de piment précoces et d'autres tardives. Ben Mansour-Gueddes et al. (2010) ont aussi établi des différences significatives entre différentes variétés de piment par rapport au délai floraison et relevé l'importance du caractère de la précocité dans la sélection des variétés de piment. En outre, quand on sait que nos plantules ont été repiquées au champ à 33 jours après le semis en pépinière, les délais de 30 à 60 Jours après le repiquage (JAR) observés pour la floraison des lignées de piment évaluées correspondraient aux délais de 60 à 90 jours après semis soutenus par Grubben \& EI Tahir (2004) pour la floraison des Capsicum. Par contre, le délai de 2 à 3 mois observé entre la floraison et la première récolte obtenu dans la présente étude paraît plus long que celui de 4 à 5 semaines avancé par les mêmes auteurs pour la formation et la maturation des fruits du piment. Les lignées concernées par cette étude seraient donc caractérisées par une longue durée de maturation physiologique des fruits. Concernant les composantes du rendement, la différence significative obtenue entre les lignées de piment peut être expliquée par la différence entre elles par rapport au développement végétatif. En effet, les lignées PM17/04A (11,9 tha), PM14/04A (10,8 t/ha) et PM16/04A (8,7 t/ha) qui ont obtenu les rendements les plus élevés sont aussi classées parmi celles qui ont présenté les meilleurs développements végétatifs. Ce résultat corrobore ceux de Lannes et al. (2007), Moreno et al. (2010) et Seleshi (2011) qui ont montré des corrélations positives entre le développement végétatif et les composantes du rendement, notamment le nombre et le poids de fruits, chez le piment. En outre, l'expression des composantes du rendement chez le piment comme d'autres cultures peut être influencée par le facteur génétique des lignées et l'environnement notamment les pratiques culturales (densité des plants, effet des engrais) et les conditions climatiques. L'essai s'étant déroulé durant la petite saison pluvieuse, l'eau a été donc disponible pour le bon développement et la productivité des plantes. Marame et al. (2008) et Law-Ogbomo \& Law-Ogbomo (2010) avaient montré une différence significative entre le rendement de diverses variétés de piment et expliqué que cette différence était due à la génétique et à l'environnement. En effet, dans les conditions ambiantes, plus l'activité physiologique est élevée chez une plante, plus elle se développe végétativement; en conséquence le rendement en fruits est élevé (Faci \& Feres, 1980; Garrity et al. 1982; Lawn, 1982).

\section{Expression des paramètres sanitaires}

Sensibilité des lignées de piment au flétrissement bactérien : La répartition des lignés selon le degré de sensibilité des plants à la maladie du flétrissement bactérien peut être liée à leur génotype confirmant ainsi les travaux de Bora et al. (2011 et 2013) qui ont aussi caractérisé diverses accessions de piment selon leur degré de sensibilité au flétrissement bactérien. En Côte d'Ivoire, N'guessan et al. (2012) ont en outre montré l'existence de différents niveaux de sensibilité au flétrissement bactérien chez la tomate (même famille botanique que le piment) allant des variétés hautement sensibles au plus résistantes. Selon Messiaen et al., (1991) et Grubben \& El Tahir (2004), le flétrissement bactérien constitue une menace pour la culture du piment sur terrain contaminée dans les pays tropicaux et autres solanacées comme la tomate (Cariglia, 2007; Blancard, 2009; Fondio et al., 2013).

\section{Champignons isolés au laboratoire}

Champignons foliaires : L'isolement de Cylindrocarpon $\mathrm{sp}$. sur les feuilles de piment semble être un phénomène rare. En effet, ce champignon est décrit comme un agent pathogène de pourriture des racines, du bois et des plantes herbacées (Domsch et al. 2007). Cylindrocarpon peut causer jusqu'à $30 \%$ de perte sur le ginseng (Panax quinquefolium) selon Seifert et al. (2003). II est responsable de la pourriture noire du pied de raisin (Halleen et al., 2004, 2006), de la maladie du pommier 


\section{Fondio et al. J. Appl. Biosci. Comportement agronomique et sanitaire de nouvelles lignées de piment (Capsicum sp) dans le Sud de la Côte d'Ivoire.}

(Tewoldemedhin et al., 2010) et du chancre du hêtre (Castlebury et al., 2006). A la lecture de ces travaux, il ressort que les plantes tropicales sont peu concernées. En conséquence, des études complémentaires s'avèrent donc nécessaires pour confirmer la présence de Cylindrocarpon comme maladie du piment. S'agissant de Rhizoctonia solani isolé sur les feuilles, les fruits et tiges, ce champignon est responsable de la fonte de semis des solancées notamment de la tomate, de l'aubergine et du piment (Conn, 2006). II peut attaquer le collet, la tige et les feuilles. La présence de Rhizoctonia solani sur les feuilles et les fruits de piment (notamment de la lignée PM16/04A) est en accord avec les observations de Goldberg (1995) et de Conn (2006). Selon ces auteurs, ce champignon est responsable du flétrissement et cause d'énormes dégâts aux piments. II serait donc responsable des attaques observées sur cette lignée. En effet, contrairement aux symptômes dûs à Ralstonia solaniet la pourriture des tiges liée à Phytophthora capsici qui provoque des flétrissements brusques, Rhizoctonia solani ne provoque pas la mort immédiate de la plante car la vigueur des pieds de piment se réduit, les feuilles sèchent progressivement et la production en fruits devient de plus en plus faible (Goldberg, 1995). Pour lutter contre ce champignon du sol, il est conseillé de maintenir un bon drainage afin de réduire l'humidité du sol et d'éliminer les résidus des plants morts de la maladie, les agents pathogènes pouvant survivre dans ces débris. L'isolement du Fusarium spp sur fruits de piment est en accord avec de nombreux travaux scientifiques car cet agent pathogène attaque toutes les solanacées en particulier le piment, la tomate et l'aubergine. La fusariose est considérée comme la principale maladie destructrice

\section{CONCLUSION}

II ressort de cette étude que les lignées PM17/04A, PM57/05A, PM14/04A et PM16/04A ont été les plus performantes avec les meilleurs développements végétatifs, les rendements les plus élevés ( 8 à $12 \mathrm{t} / \mathrm{ha}$ ) et un faible niveau de sensibilité au flétrissement bactérien. Par contre, les lignées PM51/04A, PM53/04A, TL, PM15/04A et PM52/04A ont présenté un mauvais développement végétatif et les rendements les plus faibles avec 0,8 à 4 t/ha. Concernant les maladies fongiques, Cylindrocarpon sp, Rhizoctonia solani, Colletotrichum sp et Fusarium sp ont été isolés sur les lésions nécrosées des feuilles, fruits et tiges des lignées PM14/0A, PM15/0A, PM16/0A, PM17/0A, PM52/0A et PM57/0A. Les travaux au laboratoire ont permis d'isoler Cylindrocarpon sp et Rhizoctonia solani sur les feuilles de toutes les lignées de piment évaluées. Sur les fruits, du piment (Black et al., 1991; Attia \& Abada, 1994). En Côte d'Ivoire, le fusarium a été isolé pour la première fois sur le piment en 1949 à Adiopodoumé près d'Abidjan par Chevaugeon (1949) qui a noté que la fusariose attaquait préférentiellement les variétés indigènes de piment aux fruits allongés. Dans la présente étude, les variétés les plus attaquées par cet agent pathogène ont également des fruits allongés. On pourrait donc dire que la fusariose est une maladie qui persiste depuis longtemps dans la région d'Abidjan. Cette persistance serait favorisée par les conditions climatiques et édaphiques favorables de la région au développement de ce champignon. Contrairement au Cylindrocarpon, l'identification de Colletotrichum sp sur les fruits des lignées est en accord avec les observations de Black (1993), Goldberg (1995) et Reckhaus (1997) qui ont montré que ce champignon est responsable des lésions aqueuses et déprimées sur les fruits. Lakshmesha et al. (2005) ont précisé que Colletotrichum capsici constitue le principal agent pathogène responsable de l'Anthracnose des fruits du piment pouvant causer 25 à $30 \%$ de pertes en post récolte. Par ailleurs, les parasites Phytophthora capsiciet Cercospora capsici dont les symptômes ont été observés au champ n'ont pas pu être isolés au laboratoire. Pour obtenir ces deux champignons, il aurait fallu les isoler sur un milieu V8 qui est un milieu spécifique contenant plus d'éléments nutritifs que le milieu PDA (Messiaen, 1970). Cette hypothèse expliquerait la présence de Cylidrocarpon sp. qui ne semblerait pas être inféodé au piment. S'agissant du champignon qui n'a pas pu être identifié, des études appropriées plus approfondies sont donc nécessaires pour le décrire davantage.

Colletotrichum sp, Fusarium sp, Cylindrocarpon sp et Rhizoctonia solani ont été les champignons les plus fréquents chez toutes les lignées. Toutefois, sur les tiges, seules deux lignées ont hébergé des champignons; Cylindrocarpon sp. et Rhizoctonia solani ont été isolés chez PM15/04A alors que Rhizoctonia solani était uniquement observé chez PM16/04A. Les milieux de culture utilisés (PDA et eau gélosée) n'ont cependant pas permis de déterminer un champignon constamment présent sur les feuilles de toutes les lignées de piment évaluées. En perspectives, les travaux futurs pourraient porter sur l'évaluation, en milieu paysan, des meilleures lignées (PM17/04A, PM14/04A, PM57/05A et PM16/04A) en vue de leur sélection définitive pour leur culture en Côte d'Ivoire, la confirmation ou non de Cylindrocarpon sur le piment, la détermination du champignon resté 


\section{Fondio et al. J. Appl. Biosci. Comportement agronomique et sanitaire de nouvelles lignées de piment (Capsicum sp) dans le Sud de la Côte d'Ivoire.}

indéterminé et la mise au point des méthodes de lutte contre les champignons formellement déterminés (Rhizoctonia solani, Colletotrichum sp et Fusarium sp) pour une meilleure protection de la culture du piment ces agents fongiques dans le pays.

\section{REMERCIEMENTS}

Nous remercions l'AVRDC (Asian Vegetable Research Development Center) pour la fourniture des semences et l'appui financier apporté pour cette recherche.

\section{REFERENCES BIBLIOGRAPHIQUES}

Attia MFand Abada KA, 1994. Control of wilt and root-rot of pepper. $7^{\text {th }}$ Cong. of Phytopathology, April, Cairo, Egypt, pp. 397-409.

Barnett HL, Barry B, Hunter, 1972. Illustrated genera of imperfect fungi, $209 p$.

Ben Mansour-Gueddes S, Tarchoun N, Teixeira da Silva JM, Saguem S, 2010. Agronomic and chemical evaluation of seven hot pepper (Capsicum annuum L.) populations grown in an open field. Fruit, Vegetable and Cereal Sci. Biotechnol., 4: 93-97.

Black LL, Green SG, Poulos JM, 1993. Maladies du poivron: un guide pratique. Tainan, Taïwan (R.O.C): AVRDC, 98 p.

Blancard D, 2009. Les maladies de la tomate, éditions Quae, $679 \mathrm{p}$.

Bora GC, Devi J, Gogoi S, Deka A, Bhattacharyya A, Paswan $L, 2011$. Evaluation of varieties of brinjal (Solanum melongena L.) for resistance to bacterial wilt in North East India. Curr. Adv. Agr. Sci., 3(1): 36-38.

Bora GC, Saikia L, Bhattacharyya A, Hazarika GN, 2013. 'Abu' and 'Bhupendra'- two promising brinjal (Solanum melongena L.) varieties suitable for cultivation under changing climatic conditions of NE India. Proceedings of the XV EUCARPIA Meeting on Genetics and Breeding of Capsicum and Eggplant 2-4 September 2013, Torino-Italy. Editors Sergio Lanteri and Giuseppe Leonardo Rotino: Breakthroughs in the Genetics and Breeding of Capsicum and Eggplant, pp. 29-31.

Cariglia A, 2007. Lutte préventive contre le flétrissement bactérien en culture de la tomate hors-sol. État des connaissances et conseils. Pôle de protection des plantes, Réunion, St-Pierre.

Chevaugeon J, 1949. Une fusariose du piment en Côte d'Ivoire. Institut intercolonial d'Adiopodoumé, Côte d'Ivoire. Collection de Référence ORSTOM, $6 \mathrm{p}$.

Conn K, 2006. Pepper \& Eggplant Disease Guide. A Practical Guide for Seedsmen, Growers and
Agricultural Advisors. 37437 State Highway 16 Woodland, CA 95695, 74 p.

Domsch KH, Gams W, Anderson TH, 2007. Compendium of Soil Fungi, 2nd edn. IHW,

Eching El-Ghoraba AH, Javedb Q, Anjumb FM, Hamedc SF, Shaabana HA, 2013. Pakistani Bell Pepper (Capsicum annum L.): Chemical Compositions and its Antioxidant Activity. Int. J. Food Prop., 16 (1): 18-32.

Faci JM \& Fereres E, 1980. Responses of grain sorghum to variable water supply under two irrigation frequencies. Irrigation Sci., 1: 149-159.

FAO, 2014. FAOSTAT Database. Food and Agriculture Organization, Roma, Italy. Available online at URL: www.fao.org.

Fondio L, Djidji AH, N'gbesso MFDP, Koné D, 2013. Evaluation de neuf variétés de tomate (Solanum Lycopersicum L.) par rapport au flétrissement bactérien et à la productivité. Int. J. Biol. Chem. Sci., 7(3): 1078-1086.

Garrity DP, Watts DG, Cillivan CY, Jilley JR, 1982. Moisture deficits and grain sorghum performance: evapotranspiration-yield relationships. Agron. J., 74: 815-820.

Goldberg NP, 1995. Extension plant pathologist: Chile pepper diseases. College of Agriculture and Home Economics, New Mexico State University, $27 \mathrm{p}$.

Grubben GJH \& El Tahir IM, 2004. Capsicum annuum L. In: Grubben GJH et Denton OA (Editeurs). Ressources végétales de l'Afrique tropicale 2. Légumes. Fondation PROTA, Wageningen, Pays-Bas: Backhuys Publishers, pp. 172-183.

Halleen F, Schroers H-J, Groenewald JZ, Crous PW, 2004. Novel species of Cylindrocarpon (Neonectria) and Campylocarpon gen. nov. associated with black foot disease of grapevines (Vitis spp.). Stud. Mycol., 50: 431-455.

Halleen F, Schroers HJ, Groenewald JZ, Rego C, Oliveira H, Crous PW, 2006. Neonectria liriodendri sp. nov., the main causal agent of 


\section{Fondio et al. J. Appl. Biosci. Comportement agronomique et sanitaire de nouvelles lignées de piment}

(Capsicum sp) dans le Sud de la Côte d'Ivoire.

black foot disease of grapevines. Stud. Mycol., 55: 227-234.

Koffi AC, Koffi-Nevry R, Kouassi KC, Loukou YG, 2014. Activité des extraits de six variétés de piment (Capsicum) utilisés en Cote d'lvoire. J. Appl. Biosci., 82: 7379-7388.

Koffi-Nevry R, Kouassi C, Nanga Z, Koussémon M, Loukou G, 2012. Antibacterial activity of two bell pepper extracts: Capsicum annum L. and Capsicum frutescens. Int. J. Food Prop., 15: 961-971.

Kouassi C, 2012. Potentialités bioactives et activité antimicrobienne des variétés de piment (Capsicum) cultivées en Côte d'Ivoire. Thèse de Doctorat; Université d'Abobo-Adjamé, Abidjan, Côte d'Ivoire, $161 \mathrm{p}$.

Lakshmesha KK, Lakshmidevi N, Aradhya SM, 2005. Changes in pectinase and cellulase activity of Colletotrichum capsici mutants and their effect on anthracnose disease on capsicum fruit. Arch. Phytopathol. Plant Prot., 38 (4): 267-279.

Lannes SD, Finger FL, Schuelter AR, Casali VWD, 2007. Growth and quality of Brazilian accessions of Capsicum chinense fruits. Sci. Hortic., 112: 266270.

Lawn RJ, 1982. Response of four grain legumes to water stress in south-east Queensland. III. Dry matter production, yield and water use efficiency. Aust. J. Agr. Res., 33: 497-509.

Law-Ogbomo KE \& Law-Ogbomo JE, 2010. Characterization and evaluation of some cultivars of sweet pepper (Capsicum annuum). Not. Sci. Biol., 2(1): 49-54.

Leug WTW, Busson F, Jardin C, 1968. Food composition table for use in Africa. Rome, Italie: FAO, $306 \mathrm{p}$.

Lin S, Chou Y, Shieh H, Ebert AW, Kumar S, Mavlyanova R, Rouamba A, Tenkouano A, Afari-Sefa V, Gniffke PA, 2013. Pepper (Capsicum spp.) Germplasm Dissemination by AVRDC - The World Vegetable Center: an Overview and Introspection. ISHS. Chron. Horticult., 53(3): 2127.

Mahbou-Somo-Toukam G, 2010. Diversité de Ralstonia Solanacearum au Cameroun et bases génétiques de la résistance chez le piment (Capsicum Annuum) et les Solanacées. Plant breeding. AgroParisTech 10, French. <NNT: 2010AGPT0021> <pastel-006007879>.

Marame F, Desalegne L, Singh H, Fininsa C, Sigvald, 2008. Genetic components and heritability of yield and yield related traits in hot pepper. Res. J. Agric. Biol. Sci., 4: 803-809.

Messiaen CM, Blancard D, Rouxel F, Lafon R, 1991. Les maladies des plantes Maraîchères. 3rd Edition. INRA, Paris, France, $552 \mathrm{p}$.

Messiaen CM \& Lafon R, 1970. Les maladies des plantes maraîchères. Paris, France: INRA, $440 \mathrm{p}$.

Moreno MM, Moreno C, Villena J, Mancebo I, 2010. "Agro-morphological characterization of 16 traditional pepper (Capsicum annuum L.) cultivars from Castilla-La Mancha (central Spain). III International Symposium on Plant Genetic Resources, Vol 2: 551-557.

N'guessan CA, Abo K, Fondio L, Chiroleu F, Lebeau A, Poussier S, Wicker E, Koné D, 2012. So near and yet so far: the specific case of Ralstonia solanacearum populations from Côte d'Ivoire in Africa. Phytopathology, 102: 733-740.

Reckhaus $P, 1997$. Maladies et ravageurs des cultures maraîchères: à l'exemple de Madagascar. République Fédérale d'Allemagne: Editions Margaf Verlag, $402 p$.

Sanogo S \& Carpenter J, 2007. Geographical Distribution and Causal Agents of Chile Pepper Wilt in New Mexico. Agricultural Experiment Station College of Agriculture and Home Economics New Mexico, $8 \mathrm{p}$.

SAS, 2003. Statistical Analysis System user's guide. SAS Institute, N.C. State University, USA, $650 \mathrm{p}$.

Segnou J, Amougou A, Youmbi E, Njoya J, 2013. Effect of Chemical Treatments on Pests and Diseases of Pepper (Capsicum annuum L.). Greener J. Agr. Sci., 3 (1): 12-20.

Seifert KA, McMullen CR, Yee D, Reeleder RD, Dobinson $\mathrm{KF}, 2003$. Molecular differentiation and detection of ginseng-adapted isolates of the root rot fungus Cylindrocarpon destructans. Phytopathology, 93: 1533-1542.

Seleshi D, 2011. Evaluation of Elite Hot Pepper Varieties (Capsicum species) for growth, dry pod yield and quality under Jimma condition, South West Ethiopia. Master's thesis of Science in Horticulture (Vegetable Science). School of Graduate Studies, College of Agriculture and Veterinary Medicine: Jimma University.

Tewoldemedhin YT, Mazzola M, Mostert L, McLeod A, 2010. Cylindrocarpon species associated with apple tree roots in South Africa and their quantification using real-time PCR. Eur. J. Plant Pathol., doi:10.1007/s10658-010-9728-4. 

(Capsicum sp) dans le Sud de la Côte d'Ivoire.

Truong HTH, Kim JH, Cho MC, Chae SY, Lee HE, 2013. Identification and development of molecular markers linked to Phytophthora root rot resistance in pepper (Capsicum annuum L.). Eur. J. Plant Pathol., 135 (2): 289-297.

Zhani K, Hamdi W, Sedraoui S, Fendri R, Lajimi O, Hannachi C, 2015. Agronomic evaluation of Tunisian accessions of chili pepper (Capsicum frutescens L.). Int. Res. J. Eng. Technol. Volume: 02 Issue: 04 (IRJET) e-ISSN: 23950056. July-2015 www.irjet.net.

Zhani K, Hermans N, Ahmad R, Hannachi C, 2013. Evaluation of Salt Tolerance ( $\mathrm{NaCl}$ ) in Tunisian Chili Pepper (Capsicum frutescens L.) on Growth, Mineral Analysis and Solutes Synthesis. J. Stress Physiol. Biochem., 9 (1): 209-228. 